\title{
Increase OEE at Manual Assembly Lines by Data Mining
}

\author{
P. Dobra ${ }^{1, *}$, J. Jósvai ${ }^{2}$ \\ ${ }^{1}$ Adient Hungary Kft \\ Hammerstein u. 2, 8060, Mór, Hungary \\ "E-mail: peter.dobra@freemail.hu \\ ${ }^{2}$ Széchenyi István University, Department of Vehicle Manufacturing \\ Egyetem tér 1, 9026, Győr, Hungary
}

\begin{abstract}
The industrial companies often use Key Performance Indicators (KPI) to follow up and evaluate their process and success. One of the KPIs is the Overall Equipment Effectiveness (OEE) which represents the efficiency of the manufacturing area. The high OEE value means good performance of the machines or lines. This paper presents a method in order to increase OEE at the manual assembly lines by data mining. Firstly, a literature review demonstrates scientific relevance. Secondly, a method is introduced for improving the efficiency with the help of the recognised patterns. Using Manufacturing Execution System (MES) data the OEE percentage was increased by $8 \%$ in 3 months without any financial investment.
\end{abstract}

Keywords: OEE; data mining; MES; assembly line; KDD

\section{Introduction}

For the elaboration of Balanced Scorecard (BSC) in business life the Financial Perspective, the Customer Perspective, the Internal Business Perspective and the Innovation and Learning Perspective are emphasised [1]. The fulfilment of the strategic objectives are defined by the Key Performance Indicators (KPI). Within the frames of the concept of Total Productive Maintenance (TPM) at manufacturers Overall Equipment Effectiveness (OEE) is applied as the most widespread indicator [2]. The efficiency of the machinery and the production lines can be indicated with 
the aid of this indicator. In order to define this indicator loads of data are required, as besides the individual values it is also important to keep up to date with the trends.

Due to a wide range of applications of data collecting there are more and more data at the corporations. In most cases only the fraction of the data mining opportunity is utilized [3]. It is particularly true in case of specific manufacturing data, where hidden patterns are not revealed, thus the potential of continuous improvement cannot be realized [4]. It is a current issue nowadays: 'How are organizations using analytics to gain insight and guide actions?' [5].

\section{Literature review}

\subsection{Data mining in manufacturing}

Monitoring of production patterns started in the second half of 1980s [6]. Due to the high amount of the data, manual analysis was not effective and efficient [7]. Data mining appeared in the 1990s, as such a data processing that could reveal valid, novel and potentially useful information form the data sets, and that could identify patterns [8]. Data mining process is a part of Knowledge Discovery in Database (KDD). The widely used KDD process is indicated by the Fig. 1. [9].

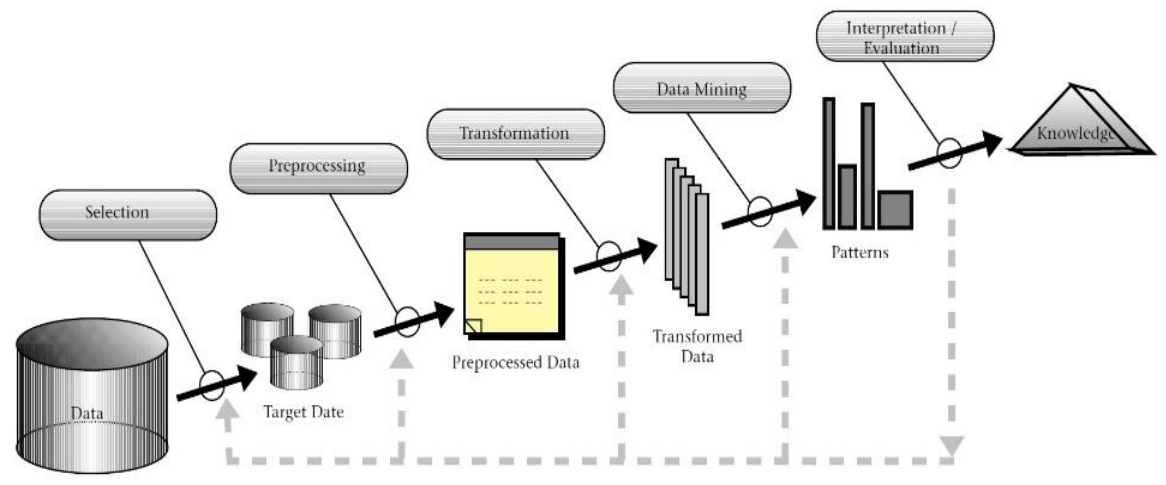

Figure 1. KDD process [9]

One of the most widespread data mining processes (Fig. 2.) is the Cross Industry Standard Process for Data Mining (CRISP-DM) which is independent of both the industrial sector and the technology [10]. 


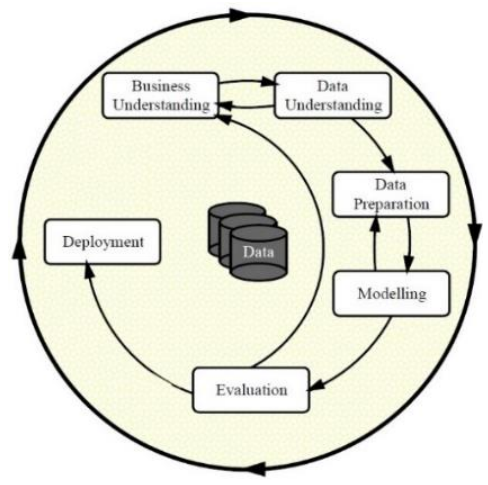

Figure 2. CRISP-DM process model for data mining [10]

SEMMA, SolEuNet, Kensington Enterprise Data Mining and the DMG among others, established methodologies, developed languages and software tools for data mining standardization [11].

Huber et al. extended the CRISP-DM model with 3 new elements: technical understanding, technical realization and technical implementation. Data Mining Methodology for Engineering (DMME) is displayed with Fig. 3. [12].

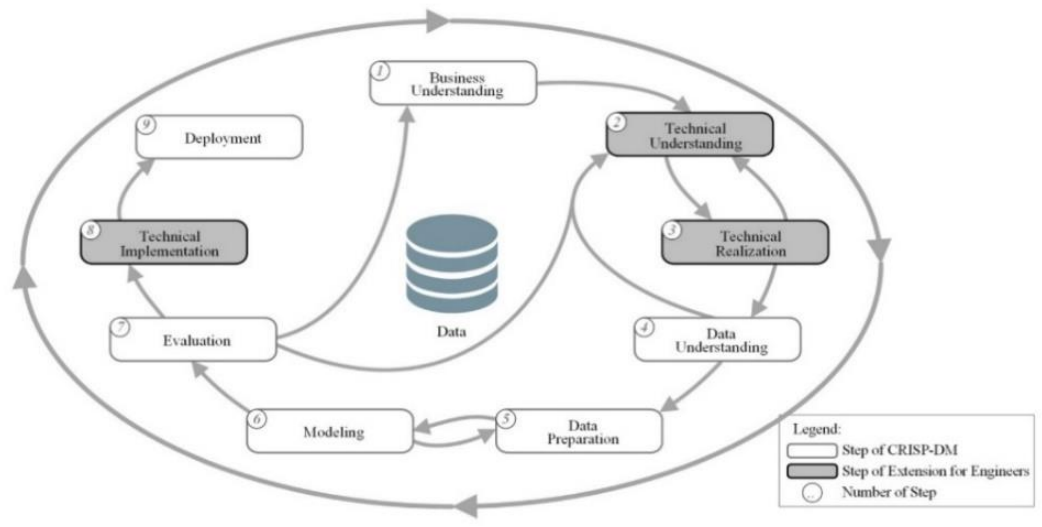

Figure 3. The DMME process [12]

Gröger et al. presented indication-based and pattern-based manufacturing process optimization as novel data mining approaches provided by the Advanced Manufacturing Analytics Platform (AdMA). AdMa is an integrated Business Intelligence (BI) platform for holistic data-driven manufacturing process optimization [4]. 
According to Buer et al. the ground of data-driven models is that due to increased computing power the analysis of big data. It facilitated revealing such patterns that human beings not necessarily would have found [13]. Fig. 4. shows the data driven process improvement cycle.

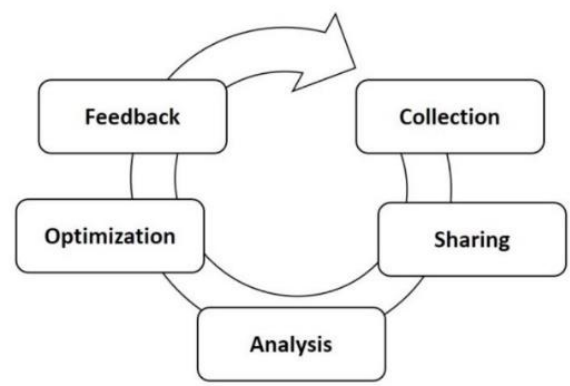

Figure 4. The data-driven process improvement cycle [13]

Agard et al. presented a model and an algorithm for selection of subassemblies based on the analysis of prior orders received from the customers. The parameters of this concept are generated using association rules extracted by a data mining algorithm [14].

In the area of manufacturing, description and prediction are the two high level goals of data mining. Descriptive data mining focuses on discovering patterns to describe data. Predictive data mining focuses on predicting the behaviour of a model and determining future value based on existing information [15].

Clustering is an essential data mining function performed on specified manufacturing data. Clustering techniques are in the following categories as: partitioning methods, hierarchical methods, density based methods, grid based methods and model based methods [15]. In the field of manufacturing Backus compared the Clustering, K-Nearest Neighbours and Regression Trees methods in order to predict cycle time [16]. Öztürk used regression tree approach in make-toorder manufacturing lead time estimation [17]. Meidan used machine learning and data mining methods to identify the cycle time key factors in manufacturing [18]. Denkena et al. used the Pearson-Correlation to identify potential dependencies [7].

\subsection{OEE as a KPI}

OEE as a KPI is a valuable tool to reveal the hidden capacity. This indicator was first introduced by Nakajima in 1988. There are six major losses to be addressed in the production system in order to improve OEE value: 
- equipment failure,

- $\quad$ setup and adjustment,

- idling and minor stoppage,

- $\quad$ reduced speed,

- reduced yield,

- defect in the process.

OEE is an excellent tool to calculate the utilisation of a production line for a given manufacturing process [19].

The basic formula for calculating OEE is written as:

$$
O E E=\operatorname{apq}[\%]
$$

where $a$ - availability [\%]; $p$ - performance [\%]; $q$ - quality [\%].

Availability indicates the performance of the maintenance and its value is given:

$$
a=\frac{a_{r t}}{p_{r t}} 100[\%]
$$

where $a_{r t}$ - actual run time; $p_{r t}$ - planned run time.

$$
a_{r t}=p_{r t}-i_{t}
$$

where $i_{t}$ - idle time.

Performance indicates the operators' performances and its value is given:

$$
p=s_{\text {or }} n_{\text {or }} 100 \text { [\%] }
$$

where $s_{o r}$ - speed operator rate; $n_{o r}$ - net operator rate.

$$
s_{\text {or }}=\frac{c_{s}}{c_{r}} 100[\%]
$$

where $c_{s}$-standard cycle time; $c_{r}$ - real cycle time.

$$
n_{\text {or }}=\frac{n c_{s}}{a_{r t}} 100[\%]
$$

where $n$ - number of products.

Quality indicates the process capability and its value is given:

$$
q=\frac{q_{p r}}{q_{p}} 100[\%]
$$


where $q_{p r}$ - quantity produced right; $q_{p r}$ - quantity produced [20].

Nowadays, manufacturers monitor their performance via Manufacturing Execution System (MES). According to the research of Subramaniyan in 2015, based on the performance of 884 machines of 23 corporations at the mechanical workshops, the average value of OEE was 65\% [19]. The OEE values of manual assembly lines are usually higher than this.

\section{Method, patterns and case study}

\subsection{Manufacturing circumstances}

The manual assembly line displayed at Fig. 5. directly transports medium sized products in an automotive factory. The line consists five work stations (W1, W2, .. W5), green colour indicates the manual work stations, grey represents the quality check work station. The blue arrow shows the direction of material and flow.

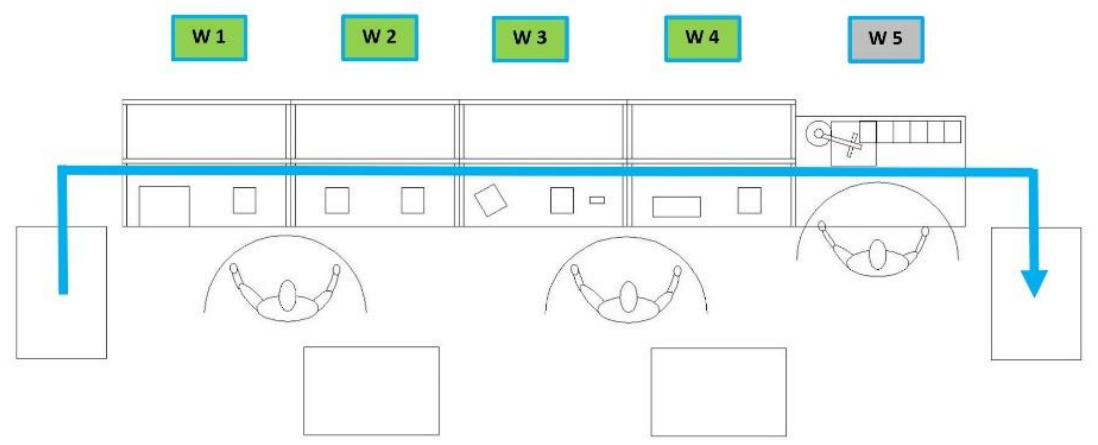

Figure 5. Manual assembly line

The assembly line has been operating for more than 12 years, in 2-3 shifts upon request to produce generally 220 products per shift. Since the beginning of the production the assembly line produces the same main product, there is no significant difference between the product variations. The work stations have different cycle time, but the bottleneck is at the end, at W5 work station. Table 1. shows the main features of the assembly line. 
Table 1. Data of assembly line

\begin{tabular}{|c|c|c|c|c|}
\hline Workstation & MES & Process & Operator & Cycle time (s) \\
\cline { 1 - 3 } W1 & - & Manual assembly & \multirow{2}{*}{ A } & 74 \\
\cline { 1 - 3 } W2 & - & Manual assembly & & \multirow{2}{*}{ B } \\
\cline { 1 - 3 } W3 & - & Manual assembly & 102 \\
\hline W4 & - & Manual assembly & & 105 \\
\hline W5 & yes & Quality check & C & 105 \\
\hline
\end{tabular}

\subsection{Patterns in MES}

MES collects, records and stores all the features and measuring data of each product (e.g.: power, amperage, noise, time, serial number, etc.), however, the fault registration of downtime is not elaborated at this production line. The data can be collected from MES with the aid of SQL (Structured Query Language) and can be processed with the data processing module of Microsoft Excel.

The basis of searching the pattern is to collect an exact timestamp to the recorded parameter (e.g.: 09:32:15, 14 ${ }^{\text {th }}$ January 2020.). According to this method the focus is on the particular piece time of the 2 manufactured products. There is an estimated value of $105 \mathrm{~s} \pm 10 \%$, exceeding values and corresponding time-date stamps are investigated. The $\pm 10 \%$ limit is the deviation of expected speed of the operator.

If, $\quad \mathrm{P}_{1}=$ the manufacturing time of the first product

$\mathrm{P}_{2}=$ the manufacturing time of the second product

$\mathrm{T}=$ the expected piece time of manufacturing of the product (in this particular case: $105 \mathrm{~s}$ )

So the possible cases are the following ones:

$$
\begin{aligned}
& \text { a, } \mathrm{T}-10 \% \leq \mathrm{P}_{2}-\mathrm{P}_{1} \leq \mathrm{T}+10 \% \\
& \text { b, } \mathrm{P}_{2}-\mathrm{P}_{1}<\mathrm{T}-10 \% \\
& \text { c, } \mathrm{P}_{2}-\mathrm{P}_{1}>\mathrm{T}+10 \%
\end{aligned}
$$

In the case of 'a', production is going well, the accomplished piece time may change within the previously defined limits, but the targeted OEE value could be fulfilled. In the case of ' $b$ ', the product gets done within a shorter piece time than expected that refers to the differences regarding the process, namely some prescribed step may be missing, or mixed up or united. The OEE value will rise, but it may raise quality risks. In the case of ' $c$ ' the manufacturing time of particular products increases and exceeds given limits, which refers to malfunction or downtime. This 
incident will decrease OEE value. The planned breaks and shift changes have the same effect. These effects are exception, they occur in similar time windows and are neglected.

\subsection{Results of the method}

The following OEE influencing patterns are revealed after local analysis of the production and the available data sets:

- Quality

- effective fulfilment of poka-yoke checks in each shift,

- rework activity has just a little volume, but due to technology rework can only be accomplished at the line, that reduces the OEE value (a product is ready-made within two time cycles).

- Availability

- rarely, simple malfunctions appear at the line, but they are repaired within a short period of time,

- there is a little disruption with the raw material supply of the line at the start of the shift, that generally lasts for 10 minutes,

- the planned preventive maintenance work is not systematic, it usually differs from the planned time period (usually shorter),

- distribution of breaks during work (shorter breaks) does not facilitate the continuous manufacturing process.

- Performance

- piece time has a high deviation, but its mean value is lower than expected, which is favourable (Fig. 6.),

- there is a more optimal production procedure than the prescribed steps of assembly that can result in the reduction of the cycle time,

- around the time of shift changes lower performance can be observed,

- the production of 225 pieces is characteristic to the most shifts (Fig. 7.). 


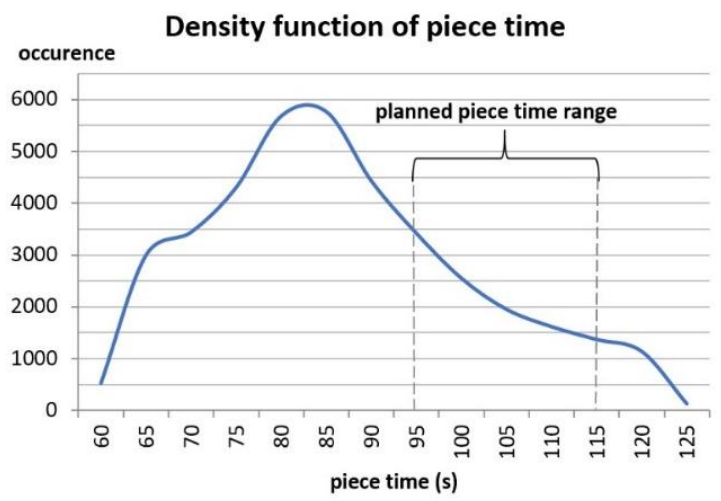

Figure 6. Density function of piece time - 2019

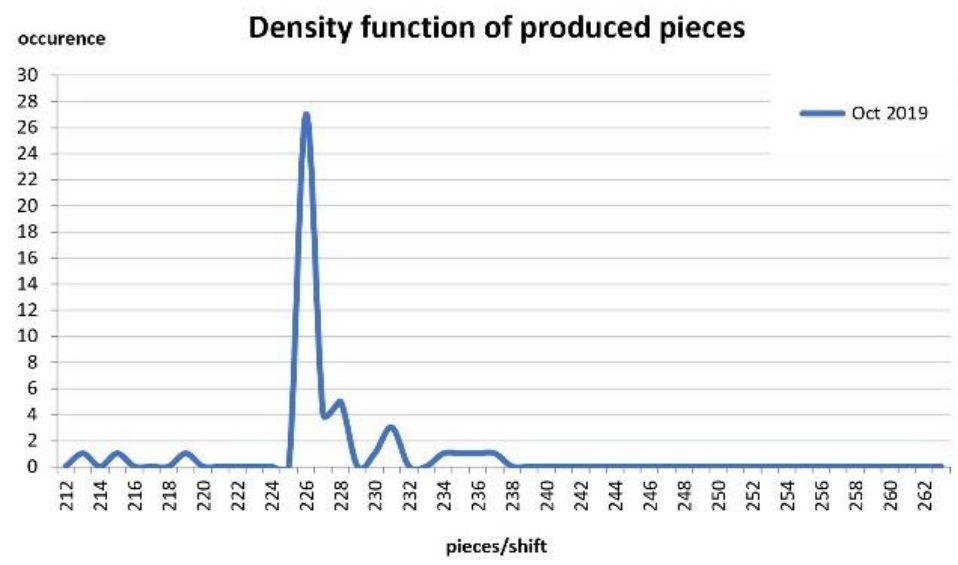

Figure 7. Density function - Oct 2019

Measures have been proposed to the revealed patterns, then after the accomplishment of the actions the following results can be observed.

- The previously experienced tendency of 225 produced pieces declined, instead of that a higher, but variable number was achieved (Fig. 8.).

- The OEE value altered from $81.5 \%$ to $90.1 \%$ from the start of the 3month-long data mining (Fig. 9.). 




Figure 8. Density function - Jan 2020

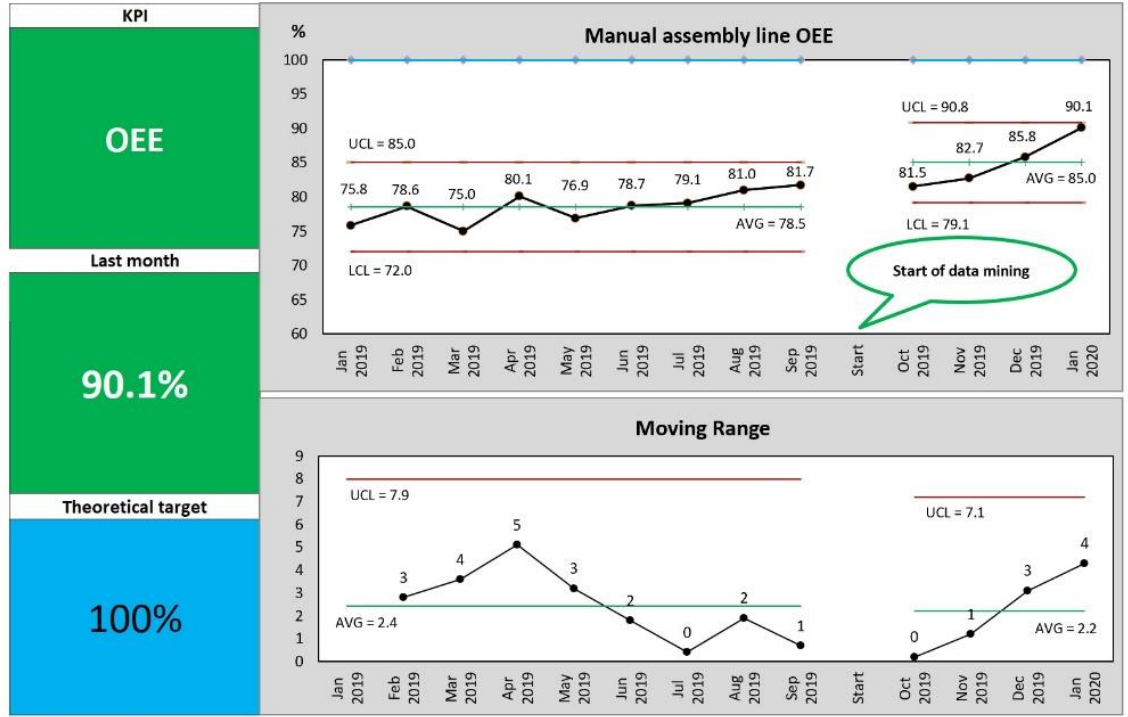

Figure 9. OEE improvement

No financial resources were used in order to increase the OEE value. Organizational and optimisation procedures were accomplished based on the patterns revealed during data mining. 


\section{Conclusion}

Based on the data deriving from MES the OEE indicator of the manual lines could be altered within a short period due to the patterns revealed during data mining. Based on the exact production time of the particular products with the altering piece time we can conclude to the changes of the OEE factors. In the following step, defined actions and countermeasures can be taken. The OEE value was increased from $81.5 \%$ up to $90.1 \%$ within 3 months and with no financial resources. The average output of assembly line was increased by only organizational and optimisation changes. The method can be applied in case of specific machines, semiautomatic and automatic assembly lines. It could be a topic of further research to analyse the time of planned and realistic maintenance work, its duration and to reveal the patterns related to them.

\section{References}

[1] R. S. Kaplan, D. P. Norton, The balanced scorecard - Measures that drive performance, Harvard Business Review 1 (1991) pp. 71-79.

[2] R. Hedman, M. Subramaniyan, P. Almström, Analysis of critical factors for automatic measurement of OEE, Procedia CIRP 57 (2016) pp. 128-133. doi: https://doi.org/10.1016/j.procir.2016.11.023

[3] G. Schuh, G. Reinhart, J.P. Prote, F. Sauermann, J. Horsthofer, F. Oppolzer, D. Knoll, Data mining definitions and applications for the management of production complexity, Procedia CIRP 81 (2019) pp. 874-879. doi: https://doi.org/10.1016/j.procir.2019.03.217

[4] C. Gröger, F. Niedermann, B. Mitschang, Data mining-driven manufacturing process optimization, Proceedings of the World Congress on Engineering 2012.

[5] S. LaValle, E. Lesser, R. Shockley, M. S. Hopkins, N. Kruschwitz, Big data, analytics and the path from insights to value, MIT Sloan Management Review 52 (2) (2011) pp. 21-32.

[6] J. A. Harding, M. Shahbaz, Srinivas, A. Kusiak, Data mining in manufacturing: A review, Journal of Manufacturing Science and Engineering 128 (2006) pp. 969-976.

doi: https://doi.org/10.1115/1.2194554 
[7] B. Denkena, M.A. Dittrich, S. Wilmsmeier, Automated production data feedback for adaptive work planning and production control, Procedia Manufacturing 28 (2019) pp. 18-23.

doi: https://doi.org/10.1016/j.promfg.2018.12.004

[8] U. Fayyad, G. Piatetsky-Shapiro, P. Smyth, The KDD process for extracting useful knowledge from volumes of data, Communications of the ACM 39 (11) (1996) pp. 27-34.

[9] U. Fayyad, G. Piatetsky-Shapiro, P. Smyth, From data mining to knowledge discovery in databases, AI Magazine 17 (3) (1996) pp. 37-54.

[10] R. Wirth, J. Hipp, CRISP-DM: Towards a standard process model for data mining, In Proceedings of the 4th International Conference on the Practical Applications of Knowledge Discovery and Data Mining (2000) pp. 29-39.

[11] J. A. Harding, M. Shahbaz, Srinivas, A. Kusiak, Data mining in manufacturing: A review, Journal of Manufacturing Science and Engineering 128 (2006) pp. 969-976.

doi: https://doi.org/10.1115/1.2194554

[12] S. Huber, H. Wiemer, D. Schneider, S. Ihlenfeldt, DMME: Data mining methodology for engineering applications - a holistic extension to the CRISP-DM Model, Procedia CIRP 79 (2019) pp. 403-408. doi: https://doi.org/10.1016/j.procir.2019.02.106

[13] S. V. Buer, G. I. Fragapane, J. O. Strandhagen, The data-driven process improvement cycle: Using digitalization for continuous improvement, IFAC PapersOnLine 51 (11) (2018) pp. 1035-1040. doi: https://doi.org/10.1016/j.ifacol.2018.08.471

[14] B. Agard, A. Kusiak, Data mining for subassembly selection, Journal of Manufacturing Science and Engineering 126 (2004) pp. 627-631. doi: https://doi.org/10.1115/1.1763182

[15] A. K. Choudhary, J. A. Harding, M. K. Tiwari, Data mining in manufacturing: a review based on the kind of knowledge, Journal of Intelligent Manufacturing 20-5 (2009) pp. 501-521. doi: https://doi.org/10.1007/s10845-008-0145-x 
[16] P. Backus, M. Janakiram, S. Mowzoon, C. Runger, A. Bhargava, Factory cycle-time prediction with a data-mining approach, IEEE Transactions on Semiconductor Manufacturing 19 (2006) pp. 252-258.

doi: https://doi.org/10.1109/TSM.2006.873400

[17] A. Öztürk, S. Kayalıgil, N. E. Özdemirel, Manufacturing lead time estimation using data mining, European Journal of Operational Research 173 (2006) pp. 683-700.

doi: https://doi.org/10.1016/j.ejor.2005.03.015

[18] Y. Meidan, B. Lerner, M. Hassoun, G. Rabinowitz, Data mining for cycle time key factor identification and prediction in semiconductor manufacturing, Proceedings of the 13th IFAC (2009) pp. 217-222.

doi: https://doi.org/10.3182/20090603-3-RU-2001.0466

[19] M. Subramaniyan, Production data analytics - To identify productivity potentials, Chalmers University of Technology, Gothenburg, Sweden, 2015

[20] M. Mainea, L. Duta, P. Ciprian, I. Caciula , A method to optimize the Overall Equipment Effectiveness, IFAC Proceedings (2010) pp. 237-241. doi: https://doi.org/10.3182/20100908-3-PT-3007.00046 